\title{
A Review on Psychological and Socio-Economic Impacts of Corona Virus Disease (Covid-19) The Case of Under Developing Countries
}

\author{
Desalegn Wondim Alene*
}

Debre Markos University, Ethiopia

Received: 08 September, 2020

Accepted: 19 November, 2020

Published: 20 November, 2020

*Corresponding author: Desalegn Wondim Alene, Debre Markos University, Ethiopia, Tel: +251960827316; E-mail: desalegnw.2321@gmail.com

https://www. peertechz.com

Check for updates

\begin{abstract}
A history signifies that there were different pandemic diseases across the globe at different times that brings a fundamental consequence in psychological, socio-economic and political situations. Evidences showed that most emergency diseases were geographically restricted while others were/are not that attracts the professionals in developing insight and taking cross cutting decision. COVID-19 is the newly emerged pandemic across the globe at the end of 2019 but still shivering the world. Evidences indicated that many countries in the world invest their time, money, energy and strategy to tackle COVID-19 with heavy hesitation for future market instability, hunger and other silent killer diseases as their current plan do not glance to them. c
\end{abstract}

\section{Introduction}

\section{History and situation of different pandemic diseases across the globe}

Different books, articles and records implied that there were the outbreaks of different pandemic diseases at different times in the world. For instance, today, the burden of deaths and disability in developing countries caused by non-communicable diseases, particularly cardiovascular conditions, outweighs that imposed by long standing communicable diseases (WHO, 2003). According to (Huremović, 2019), intermittent outbreaks of infectious diseases have had profound and lasting effects on societies throughout history. For instance, those events have powerfully shaped the economic, political, and social aspects of human civilization, with their effects often lasting for centuries. Epidemic outbreaks have defined some of the basic tenets of modern medicine, pushing the scientific community to develop principles of epidemiology, prevention, immunization, and antimicrobial treatments.

Moreover, Delivorias and Scholz [1] revealed that "despite significant medical progress over the last centuries, infectious diseases such as influenza or malaria still represent a considerable threat to society. While some are endemic to specific geographical regions, others can spread, becoming epidemics or pandemics. While the first and most crucial aspect of an epidemic is, and will always remain, the loss of human life, the spread of a virus can also have important repercussions for national or regional economies".

A pandemic is an epidemic occurring on a scale which crosses international boundaries, usually affecting a large number of people. In a simple way a pandemic is an epidemic with higher magnitude in terms of geographical area, number of cases and days of suffering resulting in disabilities or deaths. Human population have suffered from many pandemics throughout history be it the earlier form of smallpox or tuberculosis or the recent incidence of HIV/AIDS or H1N1. It has created catastrophic damage in many different forms. Public health around the globe is improving by leaps and bound but the occurrence of a pandemic is not always unexpected. The epidemiological transition in different form may be one of the important factors for such incidents in and around the globe (Samal, 2014). 
Damir Huremović (2019) a guest editor, for the nature public health emergency listed different outbreak diseases at different times in the world(like, the Athenian Plague,430B.C., Antonine Plague, the Justinian Plague, the black death, the Plague doctor, "Spanish flu" pandemic 1918-1920, HIV pandemic, smallpox outbreaks in former Yuguslavia,1972, SARS, H1N1/09 Pandemic, Ebola outbreak (2014-16), ZIKA(2015-16) and Disease X). At that time surprisingly, the writer stated that "disease $\mathrm{X}$ is not, as of yet, an actual disease caused by a known agent, but a speculated source of the next pandemic that could have devastating effects on humanity" which can signifies COVID-19 and other future possible world or some region pandemic diseases.

\section{Objectives of the review}

1. To understand psychological and socio-economic impacts of COVID-19 in this short period

2. To see the swinging situation of the virus in developing nation's socio-economic situation across the glob

3. To combed the different short review and create awareness about COVID-19

Zhang and Feei Ma conducted online cross sectional survey through social Medias about COIVD-19 in China, Liaoning Province particularly on respondents aged groups' $\geq 18$ years old on the impact of corona virus disease on mental health and quality of life among local residents and the result revealed that majority of participants $(53.3 \%)$ did not feel helpless due to the pandemic.

This result indicated that technology dependence societies in their socio-economic life shared updated events and thus simplified their life in turn shaped their psychological view. But this fact depends on the nation's attention to their psychological and socio-economic emphasize in line with current situation.

Moreover the above study explained that $52.1 \%$ of participants felt horrified and apprehensive due to the pandemic and regarding to help, the majority of participants (57.8-77.9\%) received increased support from friends and family members, increased shared feeling and caring with family members and others. Finally the study concludes that the COVID-19 pandemic was associated with mild stressful impact on the sample population under study, even though the COVID-19 pandemic is still ongoing. Here remember should be given back to the history of china great diseases writers considered Black Death [2]; "The Plague" was a global outbreak of bubonic plague that originated in China in 1334, arrived in Europe in 1347, following the Silk Road. Within 50 years of its reign, by 1400 (The Encyclopedia Britannica, 2018) it reduced the global population from 450 million to below 350 million, possibly below 300 million, with the pandemic killing as many as 150 million. Some estimates claim that the Black Death claimed up to $60 \%$ of lives in Europe at that time [3].

Reports from TRALAC (2020) explained that COVID-19 crisis is affecting the entire world economy in general and that of Africa in particular. Some key sectors of the African economy are already experiencing a slowdown as a result of the pandemic like Tourism, air transport, and the oil sector are visibly impacted. However, invisible impacts of COVID-19 are expected in 2020 regardless of the duration of the pandemic. OECD [4] write a report on the socio-economic implication and policy response of the virus and stated that although the number of COVID-19 cases and fatalities might still appear comparatively low in Africa than in other world regions, the looming health shock of COVID-19 could have disastrous impacts on the continent's already strained health systems, and could quickly turn into a social and economic emergency. Beyond health risks, the COVID-19 shock to African economies is coming in three waves that:

i. Lower trade and investment from China in the immediate term;

ii. A demand slump associated with the lockdowns in the European Union and OECD countries; and

iii. A continental supply shock affecting domestic and intra-African trade. It is shaking commodity-driven growth models that had largely failed to create more and better jobs or improve well-being.

World Health Organization (WHO) declared the outbreak of a new coronavirus disease; COVID-19, to be a Public Health Emergency of International Concern that WHO and public health authorities around the world are acting to contain the COVID-19 outbreak. Early in the occurrence of the disease peoples in different parts of the world particularly developing nations like Ethiopia considered as joking and rather than save oneself from contamination and stay at home they celebrating different cultural phenomena together as like as the secured time.

In Ethiopia, the outbreak of the disease was officially announced in March 13, 2020, The Federal Ministry of Health has confirmed a coronavirus disease (COVID-19) case in Addis Ababa, Ethiopia. The case, which was announced on the 13th of March 2020, is the first one to be reported in Ethiopia since the beginning of the outbreak in China in December 2019 (WHO, 2020).

In Ethiopia, COVID-19 was the only talk in the first one to two months from officially announced time in tea coffee and other cultural ceremonies but still forgetting ways of transmission from infected to the healthy one.

With no glance to investment, agriculture and even other silent killer diseases, social Medias like Facebook, twitter and email addresses as well as Ethiopia television and other private communication Medias in all over the country talk and teach to the different level of the society using different languages and techniques about corona virus disease but nobody has hesitate and nothing to change and shaped. After hearing the death news in the country, peoples started to frustrated and increase absentee from daily activities.

UNICEF [5] telling the impact of the virus in Ethiopia that the current COVID-19 crisis is challenging the delivery of essential services to the most affected segments of the population, 
children and families who are already vulnerable due to socio-economic exclusion or those who live in overcrowded settings are particularly at risk because of certain goods and commodities sky rocketed price and lack as well as devalued price for daily workers of ordinary citizens.

Sociocultural norms and values that are at the center of African societies now face severe risk of disappearing into oblivion due to corona virus disease. The ban on public gatherings, for instance, in response to the pandemic has had consequent impact on family and community life, increased the possibility of fracturing relationships and undermining trust between states and their citizens, with long-term implications for cohesion and social harmony, that was unique in the continent [6].

Moreover, in developing countries including Ethiopia help in daily consumption, sanitizer and other needs may arise as different short studies have signified. For instance [7] explained the virus impact on the macroeconomic and social life by using local and global media-based information, information obtained from interaction with some of the industry actors as well as his own research findings about the "Ethiopian economy to come up with the possible economic impact of the virus on the country" and revealed that that GDP may contract by 11.2 percent in 2020/21 fiscal year (that runs from July,2020- June 2021) if the economic effect of the virus lasts till the end of 2020. In the best-case scenario of the effect of the virus being limited to the first quarter of the next Ethiopian fiscal year $2020 / 21$, the GDP may contract by 5.6 percent, instead.

In the worst-case scenario of the effect hanging around for the coming three quarters, the decline in growth could be as high as 16.7 percent. In the same study, the service sector is, on average, forecasted to contract by about 15.6 percent.

From the beginning, the coronavirus disease has critically impacted global health systems and economies, especially in developing countries. Those countries have been struggling to address the preexisting burden of diseases with limited resources, which will become even more challenging during COVID-19. The economic implications related to COVID-19 in those countries include a high cost of care, market failures in pluralistic health systems, high out-of pocket expenses, the added burden of non-communicable diseases, missed economic opportunities, and socioeconomic consequences like unemployment and poverty [8].

Many African risks becoming food insecure as a consequence of COVID-19 crisis. Regarding business related activities and the care given to food security during corona virus disease in general, United nation, in May [9] explained that it is important to prioritize agriculture by declaring it a critical sector that should not be interrupted by COVID-19 related measures. Food corridors need to be secured, and farmers supported, to ensure uninterrupted supplies and food security. Similarly, focus should be on regions and communities where risks are most acute, strengthening social protection systems and safeguarding access to food and nutrition for the most vulnerable groups, especially young children, pregnant and breastfeeding women, older people and other at-risk groups [10].

\section{Conclusion and future directions}

There were the outbreaks of different pandemic diseases at different times in the world. For instance, intermittent outbreaks of infectious diseases have had profound and lasting effects on societies throughout history. For instance, those events have powerfully shaped the economic, political, and social aspects of human civilization, with their effects often lasting for centuries.

Various reports regarding to COVID-19 explained that the virus crisis is affecting the entire world economy in general and that of Africa in particular that some key sectors of the African economy are already experiencing a slowdown as a result of the pandemic like Tourism, air transport, and the oil sector are visibly impacted.

Thus, a continuous straggle should held by devising cultural, religion and environmentally fitted strategies with a great attention to malaria and other silent killer diseases in the region.

\section{References}

1. Delivorias A, Scholz N (2020) Economic impact of epidemics and pandemics Link: https://bit.ly/32Yfyvk

2. The Encyclopaedia Britannica Editors of. Black death, Encyclopædia Britannica 2018. Link: https://bit.ly/36QTWCW

3. Dewitte SN (2014) Mortality risk and survival in the aftermath of the medieval black death. PLoS One 9: e96513. Link: https://bit.ly/2IO5Tkc

4. OECD Policy Responses to Coronavirus (COVID-19) COVID-19 and Africa: Socio-economic implications and policy responses. Link: https://bit.ly/3kP4VkK

5. UNICEF (2020) Socio-economic impacts of COVID-19 in Ethiopia. Link: https://uni.cf/3fpZMid

6. Azoulay A (2020) United Nations Educational, Scientific and Cultural Organization director general.

7. Geda A (2020) The macroeconomic and social impact of COVID-19 in Ethiopia and suggested direction for policy response. Addis Ababa Univesrsity. Link: https://bit.ly/38WRVr9

8. Rodela TT, Tasnim S, Mazumber H, Faizah F, Sultana A, et al. (2020) Economic Impacts of Coronavirus Disease (COVID-19) in Developing Countries. Link: https://bit.ly/2UFYBRV

9. United Nation (2020) Impact of COVID-19 in Africa May 2020

10. https://www.tralac.org/news/article/14483-impact-of-the-coronavirus-covid19-on-the-african-economy.html.

Copyright: @ 2020 Alene DW. This is an open-access article distributed under the terms of the Creative Commons Attribution License, which permits unrestricted use distribution, and reproduction in any medium, provided the original author and source are credited. 